\title{
Data Analytics for Energy Consumption of Digital Manufacturing Systems Using Internet of Things Method
}

\author{
Jian Qin, Ying Liu, and Roger Grosvenor
}

\begin{abstract}
The topic of 'Industry 4.0' has become increasingly popular in manufacturing and academia since it was first published. Under this trending topic, researchers and companies have pointed out many related capabilities required by current manufacturing systems, such as automation, interoperability, consciousness, and intelligence. To achieve these capabilities, data is considered the vitally important connecting media that integrates different manufacturing objects and activities. Additionally, sustainability is one of the most important research areas of Industry 4.0. Although modern digital manufacturing systems are becoming increasingly automated, the issue of sustainability still attracts attention, and is related to many processing factors that are present in a wide variety of systems. As a result, defining the energy consumption behaviour of digital manufacturing systems and discovering more efficient usage methods has been established as a crucial research target. In this paper, data analysis methods are proposed to facilitate better understanding and prediction of the energy consumption of digital production processes under an Internet of Things (IoT) framework. A Selective Laser Sintering (SLS) system is applied as a case study, in which a variety of real-time raw data is collected within machine logs from this ongoing Additive Manufacturing (AM) system. The machine data logs are combined with the product layout data and analysed using three data analysis techniques: linear regression, the decision tree method and the Back-propagation Neural Network method. The future work is introduced in order to complete this research.
\end{abstract}

\section{INTRODUCTION}

It is generally understood that the forward thanking term 'Industry 4.0' was coined to highlight the presence of a new industrial revolution. Researchers and companies are currently tending towards the development of digital, flexible and stable manufacturing environments, encompassing many different manufacturing fields including factories, businesses and consumer products [1]. Benefiting from IoT technology, industry-relevant items including materials, sensors, machines, products, supply chains and customers are connected in the Industry 4.0 era. The IoT system relies on a combination of embedded hardware such as identification components, sensors and actuators, and intelligent software, which the physical system then simplifies to changeable data sequences [2]. In this integrated digital environment, data is considered to be the vitally important connecting media integrating manufacturing objects and activities. This data is generated and collected using a variety of digital technologies including monitoring, controlling identifying and many other digital technologies. According to current reports, the total

Jian Qin is with the Mechanics, Materials and Advanced Manufacturing Group, School of Engineering, Cardiff University, CF24 3AA UK (Corresponding author, phone: +44 29208 70662; fax: +44 29208 70662; email: Qinj2@cardiff.ac.uk). volume of collected industrial data has been up to 1000 Exabyte yearly and this total is projected to increase over the next few years [3]. This massive data collection includes various modalities with high-velocity generation. Using modern communication technologies, data can be easily transmitted between different manufacturing objects and can be stored in either a traditional or cloud [4]. It is generally agreed that there is great value hidden in this data, which discovering the that information has become one of the most necessary targets in the age of Industry 4.0.

Although the Industry 4.0 manufacturing process is integrated, automated, predictive and intelligent, sustainability is another important facet of a successful system [5]. At present, industrial production activities use about $35 \%$ of the entire global electricity supply and produce approximately $20 \%$ of total carbon emissions. In the last 20 years, the top five manufacturing countries have experienced an increase of more than $50 \%$ in their greenhouse gas emissions. Manufacturing sustainability has never escaped the industry's attention and is an indispensable research topic in the age of Industry 4.0. Energy consumption is considered one of the most crucial fields in manufacturing sustainability. It is known that the energy efficiency of production processes is normally below $30 \%$. For some specific processes, the losses of energy are unexpectedly high. For example, the energy loss of the rough milling process is about $60 \%$, and the finishing process is about $95 \%$ [6]. In most industrial settings, energy consumption is an of essential standard by which to measure the benefits of the business. Additionally, highly efficient energy usage can not only reduce production costs, and expand profit margins, but also solve associated environmental and social problems. As reported in An Energy policy for Europe, European industry will reduce both gas emissions and energy usage $20 \%$ before the year 2020 [7]. As a result, many manufacturing researchers have been paying close attention to the topic of energy consumption and its environmental and financial impacts. Many energy saving technologies for manufacturing including production energy consumption forecasting [8], manufacturing system energy consumption simulation [9] and smart manufacturing grids, are currently being developed and applied [10]. It is generally agreed that the energy usage of a manufacturing system is difficult to obtain using a simple mathematical model because of diversity and complexity of such systems [11].

This research targets the IoT data analysis solution which will be presented as a mode of addressing the energy

Ying Liu and Roger Grosvenor are with the Mechanics, Materials and Advanced Manufacturing Group, School of Engineering, Cardiff University, CF24 3AA UK (e-mail: LiuY81@ @ardiff.ac.uk, Grosvenor@cardiff.ac.uk). 
consumption problem in the modern digital manufacturing system. Based on IoT techniques, a multi-layered framework is designed to analyse the system. Various energy saving intelligent applications capable of matching the Industry 4.0 requirements will be presented within this framework [12]. In this paper, an IoT-based framework is generated and displayed in detail within Section II. Section III delivers a case study of the ongoing AM system. The current digital environment will be introduced in detail. In addition, an early energy consumption prediction model will be built to show the data analysis results from three different techniques. Finally, the future experiment plan of this research will be discussed in the Future Work and Closing Remark.

\section{AN INTERNET OF THINGS FRAMEWORK OF ENERGY CONSUMPTION FOR DIGITAL MANUFACTURING SYSTEM}

In the age of Industry 4.0, one of the most essential capabilities and design principles is interoperability. IoT technology has become one of the best solutions for the achievement of integrated function, generating horizontal integration, end-to-end digital integration and vertical integration in manufacturing systems [13]. In the desired interoperable manufacturing environment, a target digital manufacturing system is includes working environment, product designs, operators, and materials statements that are integrated throughout production process to generate an integral complex processing model. In this model, significant amounts of data are collected, leading to discovery of new information and applicable knowledge. Since life cycle management and energy sustainability management are two core business services desired in Industry 4.0 system and this integration not only focuses on the improvement of manufacturing production but also engages in industrial enterprise management $[5,14]$. The Service Oriented Architecture (SOA) approach is the driving design principle for the energy consumption analysis modelling of digital manufacturing systems [4]. An IoT framework is then designed based on this principle as illustrated in Fig. 1.

In this framework, there are four layers: the Processing Execution layer, the Data Integration and Pre-process layer, the Information and Knowledge Generation layer and the Application Performance layer. Each layer consists of several components, and the four layers are closely interlinked.

\section{A. Processing Execution Layer}

The Processing Execution layer is also known as the production status. This layer is responsible for processing environmental conditions within the target digital system and includes data from the working environment, materials, operators, products and other system components. In this layer, the system and its associated objects carry the most relevant data invisibly. Using a variety of sensors and components, these invisible data sets are extracted [15]. However, the digital data sets created in this layer are represented as massive and meaningless strings of number, which means they tend to be unreadable. The increased efficiency of the digital system is the main aim of this research, as the majority of energy is consumed by it. Most current digital systems have embedded sensors to obtain and collect various processing data during operation. Parts of this data set can then be related to the system energy consumption.
However, some factors in this layer may be invisible because the integrated sensors do not collect all information associated with energy consumption. The addition of extra sensors is necessary to obtain supplementary data [16]. In this layer, entire manufacturing activities are considered as the inputs of this IoT-based model. By utilizing sensing and identifying techniques, these activities are transformed into available raw data string for further analysis. The Processing execution layer is considered to be the integrative data collection and plays a crucial role in the overall framework.

Figure 1. IoT Framework of Energy Consumption Analysis

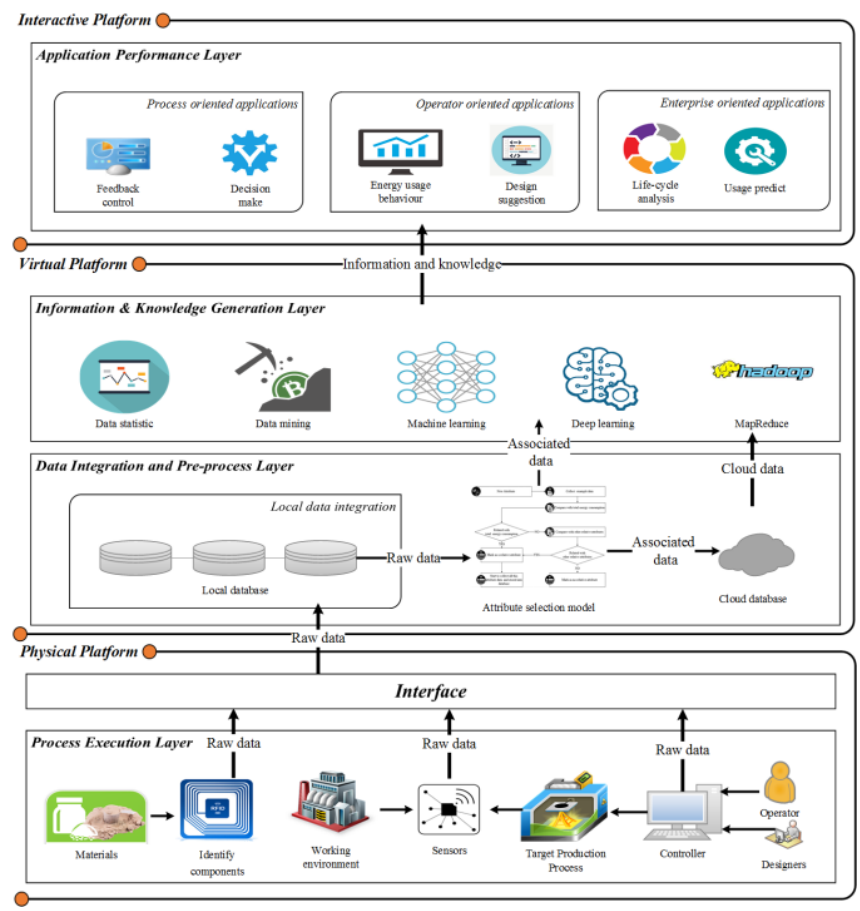

\section{B. Data Integration and Pre-process Layer}

The Data Integration and Pre-process layer is divided into three parts: local data integration, the data selection model and the cloud database. In the local data integration section, the data generated by the Process Execution layer is collected and stored in the local database. Once inside the local database, the collected system resource data is sorted and stored by production process. It is known that only a part of the collected data is related to energy consumption, which means that collection of other data would be a waste of resources within the scope of this research. Therefore, it becomes necessary to select the associated attribute data that integrates with previously selected data as the second portion of this layer, as illustrated in Fig. 2. When a new attribute is thought to be integral the data analysis model, the example data set should be tested by first matching the example data with the total energy consumption. If the result of this comparison shows a relationship, this attribute data will be marked as related data. Otherwise, the example data set will be compared with other existing related attribute data. When the new example data set shows an association with existing related data. this additional data type is added to the database. The third part of this layer is the cloud section, in which the related energy consumption data is uploaded to the cloud for further analysis [17]. In the 
cloud, data set from different machines, systems, and production processes are integrated. The Direct Attached Storage (DAS), Network Attached Storage (NAS), and distributed storage systems are considered the main storage solution models [18].

Figure 2. Data Selection Model

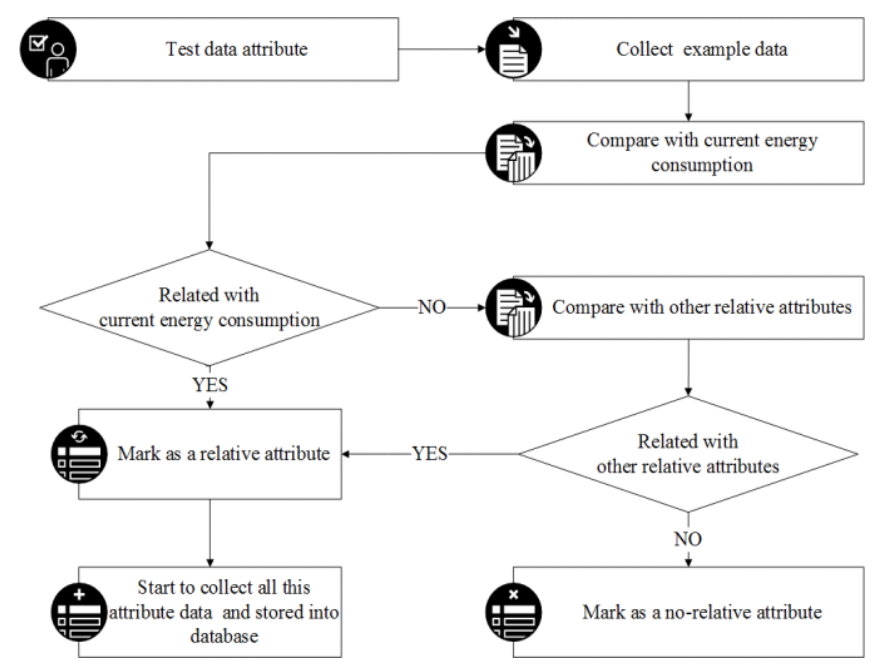

\section{Information \& Knowledge Generation Layer}

Due to the different data resources, this layer generates two types of information and knowledge: one type is from local data that is generated from the target system and local working environment, and another type is from cloud data that is collected from the cloud. Local data resources allow the relationship between system energy consumption and related attributes to be found. The energy usage behaviour is dependent upon the given situation. The trend line of energy consumption is also depicted, delivering the energy usage prediction of the target manufacturing system. This information is integrated with the generation of local processing knowledge to assist in predicting the energy usage of the system and decision- making process. The application of this prediction will be discussed later in the Application Performance layer. Theoretically, the inclusion of data from the cloud creates a body of information that is both more diversified and more accurate. In addition, the information can then be shared contributing to the research of all teams using the cloud. In this layer, various data analysis techniques are used. For local information and knowledge generation, data mining is the core technology. It is used to discover information and knowledge for future processes storage. Prior knowledge utilizes specific machine learning algorithms to identify the valuable potential of selected raw local data. Cloud information and knowledge generation fall into the big data environment, utilizing a variety of data analysis methods including bloom filter, hashing, index, the trial and parallel computing method [19].

\section{Application Performance Layer}

In the Application Performance layer, the data discovered in the the Information \& Knowledge Generation layer is displayed as a series of implementation options based on a grouping of differently oriented objects. The options can be divided into three sections: process orientated applications, operator orientated applications, and enterprise orientated applications. In the process orientated application section, the production system receives feedback from the control signals. The system then changes the settings of the relevant parameters to reduce energy consumption. These parameter changes are made by the IoT framework relying on the information analysed in the preceding layer. Operators can obtain the system energy consumption behaviour profile using the recorded production energy data to predict future energy use. The information is presented both virtually and graphically, guiding operators to utilize the system economically. In addition, they can also receive production design suggestions for improving the system design. Enterprise managers are frequently more interested in the system life cycle analyses and energy sustainability analyses that are also be delivered by this layer.

The IoT framework focuses on energy consumption in the modern digital manufacturing process, creating a new method of energy consumption analysis in the age of Industry 4.0. This framework involves numerous related factors that integrate benefits from data mining and big data analysis technology within the local data and cloud-based database. Valuable knowledge about digital manufacturing system energy consumption is generated and presented intelligently. Certain decisions are made by the framework and control system automatically. This IoT framework is able to match the required capabilities of Industry 4.0 [12].

\section{CASE STUDY}

\section{A. Literature Review and Background}

During the past two decades, AM machines have been increasingly employed in industry and academia. Due to their digitalization, automation, flexibility and customization, these machines are also becoming popular in modern industrial production. when compared with the traditional manufacturing process, the AM process is a high energy consumption system with a high production yield, especially selective laser sintering (SLS) and selective laser melting (SLM) [20]. The energy consumption of AM processing is influenced by many factors, and according to the Life Cycle Analysis (LCA) of the SLS process, energy consumption is the most important factor affecting the environmental impact of this process [21]. In addition, AM processing is a complex system because of complicated material parameters, highly automated levels, and the employment of variety of processing techniques. Even when testing on the same machine and with the same material, different processing techniques show different energy consumption performances, and making energy consumption of AM processing challenging to analyse and optimize [2224]. Although the energy consumption of AM systems is complicated because of diverse correlations, reducing energy consumption of the AM process is considered one of the crucial research targets for manufacturing sustainability in the age of Industry 4.0. Table 1 illustrates several energy consumption impact factors of the AM system as described by a selection of current literature. In the existing research, models are built for predicting energy consumption in AM processes. However, the impact is varied because there are many correlations, and it is difficult to identify all related attributes of AM process energy consumption from current research. To analyse the result accurately, the model must 
integrate as much data as possible. Therefore, the framework shown in Section II is considered as the main method of this case study.

TABLE I. ENERGY CONSUMPTION RELATED IMPACTS IN LITERATURE

\begin{tabular}{|l|l|l|l|}
\hline \multirow{2}{*}{ Literature } & \multicolumn{3}{|c|}{ Energy Consumption Related Impacts } \\
\cline { 2 - 4 } & Processing Impacts & Design Impacts & $\begin{array}{c}\text { Material } \\
\text { Impacts }\end{array}$ \\
\hline $\begin{array}{l}\text { Sreenivasan } \\
\text { and Bourell } \\
\text { [24] }\end{array}$ & $\begin{array}{l}\text { Scan speed, laser } \\
\text { power rate, build } \\
\text { platform size }\end{array}$ & Nil & $\begin{array}{l}\text { Material } \\
\text { density }\end{array}$ \\
\hline $\begin{array}{l}\text { Paul and } \\
\text { Anand [20] }\end{array}$ & $\begin{array}{l}\text { Layer thickness, } \\
\text { laser beam radius, } \\
\text { scan speed, laser } \\
\text { power }\end{array}$ & Part orientation & $\begin{array}{l}\text { Absorption } \\
\text { powder }\end{array}$ \\
\hline $\begin{array}{l}\text { Watson and } \\
\text { Taminger } \\
\text { [25] }\end{array}$ & $\begin{array}{l}\text { Feedstock \& } \\
\text { recycling } \\
\text { transported distance, } \\
\text { build platform size }\end{array}$ & $\begin{array}{l}\text { Volume of } \\
\text { material }\end{array}$ & Nil \\
\hline $\begin{array}{l}\text { Telenko } \\
\text { and } \\
\text { Speeperad } \\
\text { [26] }\end{array}$ & Nil & Z-height & $\begin{array}{l}\text { Material } \\
\text { density }\end{array}$ \\
\hline $\begin{array}{l}\text { Baumers } \\
\text { et al. [22] }\end{array}$ & $\begin{array}{l}\text { Processing } \\
\text { procedures, build } \\
\text { time }\end{array}$ & $\begin{array}{l}\text { Part geometry, } \\
\text { Z-height, } \\
\text { capacity } \\
\text { utilization }\end{array}$ & Nil \\
\hline
\end{tabular}

In this research, an SLS manufacturing system (EOS P700) was chosen as the target system. This digital manufacturing system consists of five main sub-systems: the main machine, the chiller for cooling lasers, the extractor fan, the powder hopper and mixer, and the shifter station. These five main energy consumers comprise the energy consumption of the whole production process. Because the entire system is supplied the electric power the energy consumption follows the equation (1) [21, 27].

$$
\mathrm{E}_{s}=\sum_{i=1}^{n_{c}} E_{i}=\sum_{i=1}^{n_{c}} \int_{t_{i} B}^{t_{i} F} p_{i}(t) * d t
$$

where the $\mathrm{E}_{S}$ is the total energy usage of the entire system, $E_{i}$ is the energy consumption of each sub-system. In this SLS manufacturing system, five subsystems are identified above $\left(n_{c}=5\right)$. In addition, $p_{i}$ is the power of each subsystem, $t_{i} B$ and $t_{i} F$ are the beginning time and finishing time of each process. In a completed production process, the energy consumption fluctuates because of various production situations and diverse working environments. The power of a particular subsystem, which also differs between subsystems, is difficult to determine precisely in real-time situations.

The energy consumption of the main machine is diverse depending on various impact factors. Therefore, the main machine is focused on the target process of the entire system in this paper, Fig. 3 displays a schematic layout of EOS P700 illustrating that the main machine is built as a series of power components including the laser system, heating system, feed and recycle system, build platform system and other miscellaneous. There are multiple energy consumers in each power usage grouping, which are also noted in Fig. 3 [29]. The energy consumption of the main machine can be also obtained from the equation (1) with several energy consumers. As previously discussed, this research applies the IoT framework to analysis of the energy consumption of a digital manufacturing system, as detailed in Section II and focuses on SLS manufacturing system (EOS P700).

Figure 3. Power Drains of Main Machine Adopted From [29]

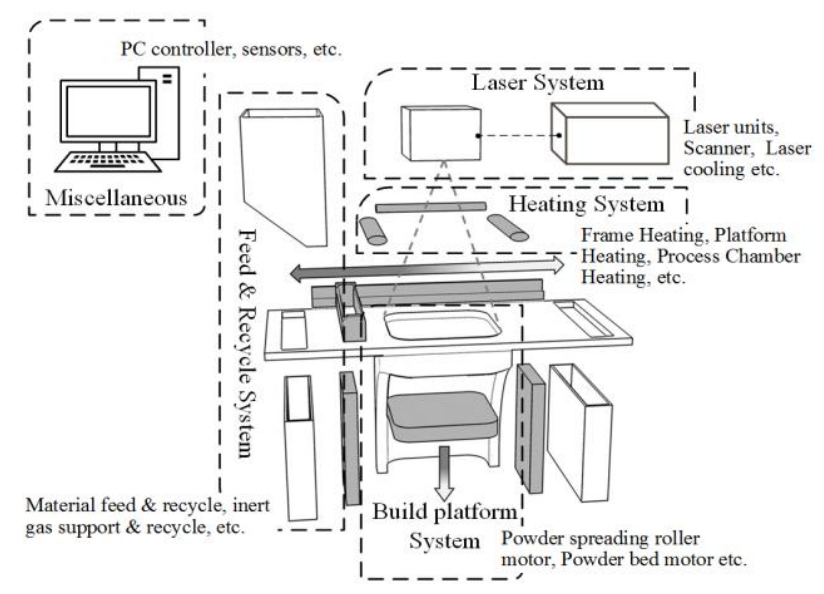

\section{B. Data Collection and Preparation}

In this production process, specific parameters are pre-set and monitored. Table II displays the process parameters set for the EOS P700 production system. The temperature and power data of main power consumers is also recorded within machine report logs. This monitoring data is generated by the system automatically with each production process, and a portion of this $\log$ is shown in Table III. There are 28 different data attributes monitored for each production layer and recorded in the machine report log.

TABLE II. PRECESS PARAMETERS SET [30]

\begin{tabular}{|l|l|}
\hline \multicolumn{1}{|c|}{ Process parameters } & \multicolumn{1}{c|}{ Values } \\
\hline Material & PA2200 \\
\hline Layer thickness & $0.15(\mathrm{~mm})$ \\
\hline Hatch distance (Scan space) & $0.3(\mathrm{~mm})$ \\
\hline Hatch speed (Scan speed) & $3000(\mathrm{~mm} / \mathrm{s})$ \\
\hline Hatch angle & $45 / 135\left(^{\circ}\right)$ \\
\hline Recoater speed & $125(\mathrm{~mm} / \mathrm{s})$ \\
\hline Laser power limitation & $70(\%)$ \\
\hline
\end{tabular}

TABLE III. Part of Machine Report Log [30]

\begin{tabular}{|c|c|c|c|c|c|}
\hline \multirow[b]{2}{*}{$\begin{array}{c}\text { Layer } \\
\text { Number }\end{array}$} & \multicolumn{5}{|c|}{ Monitoring data } \\
\hline & $\begin{array}{c}\text { Chamber } \\
\text { temperature } \\
{\left[{ }^{\circ} \mathrm{C}\right]}\end{array}$ & $\begin{array}{c}\text { Pyrometer } \\
\text { temperature } \\
{\left[{ }^{\circ} \mathrm{C}\right]}\end{array}$ & $\begin{array}{c}\text { Chamber } \\
\text { power } \\
\text { back[\%] }\end{array}$ & $\ldots$ & $\begin{array}{c}\text { Platform } \\
\text { power } \\
(\%)\end{array}$ \\
\hline 560 & 83.85 & 34.61 & 28.37 & & 14.14 \\
\hline 561 & 84.00 & 34.17 & 28.79 & & 13.88 \\
\hline 562 & 84.15 & 34.17 & 28.86 & $\cdots$ & 14.00 \\
\hline 563 & 84.30 & 34.17 & 29.42 & & 14.06 \\
\hline 564 & 84.45 & 34.72 & 28.40 & & 14.36 \\
\hline
\end{tabular}

Using data from the tables above, some basic machine situation can be monitored and recorded by embedded sensors. Based on the IoT framework, only part of this data can be related to system energy consumption when considered as input for data analysis. Some attributes, such as the backchamber power and platform power, can be identified as 
relevant energy consumption attributes. For other attributes in the data sheets, it is more difficult to clarify the relationship to system energy consumption. Therefore, selecting the correlated data attributes is necessary step in data preparation before applying further data analysis techniques. The selection method is shown in Fig. 2, Section II.

As discussed in Section II, this research relies on diverse and plentiful correlated data. The data collected from the system are far from the requirements of the IoT framework. Based on the principle of the IoT framework and the concrete situation presented in the case study, many other types of data must be collected, including product design data, working environment data, and operator activity data. Ideally, this research integrates all this data within the framework to optimize the model. However, in this paper, only part of the operator activity data is collected in order to build the optimized data analysis model.

\section{Data Analysis}

In this paper, the data is collected from a system that includes 40 production processes with 47,417 production layers. Additionally, every data set is generated for each production layer. The Linear Regression (LR), Decision Tree (DT) and Back-propagation Neural Network (BPNN) data analysis methods are to predict the total power depending on other data attributes [30]. The LR is a basic statistics analysis which detects the relationship between the target attribute and the independent attributes. The method is simply categorized into two types of regression depending on the number of independent attributes. When the model includes only one independent attribute, the modelling process is called simple linear regression. When there are multiple independent attributes in the model, the process is called multiple linear regression. Since this research involves more than ten independent attributes in building the overall relationship to total power consumption, the multiple linear regression method is used in this case study. The DT, which is structured like a flowchart, is one of the fundamental learning prediction method. The topmost node is called root, and every internal node, branch and leaf node of a decision tree represent an attribute, a result, and a class label. Depending on the attribute values, the unknown tuple is classified within individual leaf nodes that store the class information. When the target attribute is a numerical data type, this data analysis is also called as regression tree. The BPNN is a popular learning algorithm of multi-layered neural networks that includes one or many hidden layers to revise the weights. The learning process has two steps. First, the output values are received by the neural networks which are initially weighted using input values. An error signal is then obtained by comparing the actual and desired outputs. The learning algorithm of backpropagation uses this error to adjust weights of all layers from the output to the input [30]. In this case study, the 9-5-1 BPNN is used with 0.1 learn rate, which means that one hidden layer within five neural nodes is included in this neural network.

Alongside the layer data sets, the machine report logs illustrated in Table III are considered raw data. Before applying these data analysis techniques, data must to be prepared using the following calculations. First, the total power is calculated as in equation (1). Additional, the related data attributes are selected by using the energy consumption related attributes selection model shown in Fig. 2. After data preparation, the new data set includes 10 attributes: the chamber temperature, the frame temperature with four parts (front, back, left, and right), platform temperature, scanner temperature, pyrometer temperature, the $\mathrm{O}_{2}$ level, and the total power. The total power is considered as the output, and the rest of the attributes are set as the input for the model. In this case study, the Weka 3.8 software was used for applying these data analysis methods with the user interface displayed.

This paper uses the cross-validation method with ten folds to test the results. Using Weka 3.8, Table IV shows the correlation coefficient between the real total power data and predicted total power data. Furthermore, the mean squared error, the relative absolute error and root relative squared error the relative are three other validation results in this case study [30]. As discussed, the operator activity data is added in the model, which is the number of products building on the layer. This attribute can be modified by system operators before the production process. For each system cycle, the operators can design the product location on the build platform, creating different data for this attribute. This allows different operators to have different product schedules in each cycle depending on their experience. Adding this attribute can assist operators in organizing products location with lower energy consumption. In Table IV, the results of the model including operator activity data are also presented. From this table, the correlation coefficient of all data analysis models that includes the new attribute is higher than original models, demonstrating that the model becomes more accurate when adding this new attribute. Also, the results of DT and BPNN are much better than the LP, which means data mining techniques are required rather than statistics analysis.

TABLE IV. RESULTS COMPARATION

\begin{tabular}{|l|c|c|c|c|c|c|}
\hline \multirow{2}{*}{$\begin{array}{c}\text { Model } \\
\text { validation }\end{array}$} & \multicolumn{3}{|c|}{ Original Model } & \multicolumn{3}{c|}{ Optimized Model } \\
\cline { 2 - 7 } & $\boldsymbol{L R}$ & $\boldsymbol{D T}$ & $\boldsymbol{B P N N}$ & $\boldsymbol{L R}$ & $\boldsymbol{D T}$ & $\boldsymbol{B P N N}$ \\
\hline $\begin{array}{l}\text { Correlation } \\
\text { coefficient }\end{array}$ & 0.49 & 0.91 & 0.86 & 0.50 & 0.93 & 0.91 \\
\hline $\begin{array}{l}\text { Mean } \\
\text { absolute } \\
\text { error }\end{array}$ & 89.65 & 43.68 & 59.61 & 89.80 & 38.61 & 50.42 \\
\hline $\begin{array}{l}\text { Relative } \\
\text { absolute } \\
\text { error }\end{array}$ & $96.1 \%$ & $46.8 \%$ & $63.9 \%$ & $96.3 \%$ & $41.4 \%$ & $54.1 \%$ \\
\hline $\begin{array}{l}\text { Root } \\
\text { relative } \\
\text { squared } \\
\text { error }\end{array}$ & $86.9 \%$ & $40.7 \%$ & $50.8 \%$ & $86.4 \%$ & $35.6 \%$ & $42.0 \%$ \\
\hline
\end{tabular}

\section{FUTURE WORK AND CLOSING REMARKS}

It is seen that the model built in this paper is far from the IoT model that is proposed in Section II. Based on this IoT framework, there are several steps needed to complete this research. The first necessity is the intuitive equipment used to monitor total energy and which can collect the precise output data necessary for the model. A communicable digital power meter must be used to monitor the EOS P700 total energy consumption. Additionally, a large volume of valuable data has not been collected for analysis in combination with 
available data from outside sources. The necessary sensors and RFID system information are currently available in this research including material and order data, product design data, predefined process data, and real-time monitoring data. The cloud service is also established to allow the combination of local information with public information and information from other SLS machines. Finally, this research needs to consider the results presentation while following the guidance of IoT framework. A selection of pre-defined algorithms will process the information to produce and optimize each production; the power reducing element will be the primary position in the algorithms.

Given the huge volume of production in the era of Industry 4.0 , energy consumption is an unavoidable issue. It is an indispensable component of power source reduction, environment protection, and process life cycle analysis. The Industry 4.0 solution is designed for finding answers to this type of problem. This paper generates a service orientated IoT framework focusing on energy consumption in digital manufacturing systems to reduce the power usage during production. As proposed by industry 4.0, this IoT framework collects, integrates, and analyzes data from the entire production environment, and the discovered information, knowledge, and analyzed results are shown intelligently to different processing participants dependent upon their roles in the system. An SLS system is applied as a case study to prove the performance of the IoT framework. Moreover, much of the related works in this research area will need to be finished as most results have not yet been released. Many future works will then be enacted following the plan described here. This research is going to achieve the requirement of Industry 4.0 when the plan is completed. In order to obtain a better understanding of energy consumption, materials suppliers, machine manufacturers and academic researchers must work together to provide a feasible solution.

\section{REFERENCES}

[1] H. Lasi, P. Fettke, H.-g. Kemper, T. Feld, and M. Hoffmann, "Industry 4.0," Business \& Information Systems Engineering, vol. 6, pp. 239-242, Aug 2014

[2] J. Gubbi, R. Buyya, S. Marusic, and M. Palaniswami, "Internet of Things (IoT): A vision, architectural elements, and future directions," Future Generation Computer Systems, vol. 29, pp. 1645-1660, 2013.

[3] D. Mourtzis, E. Vlachou, and N. Milas, "Industrial Big Data as a Result of IoT Adoption in Manufacturing," Procedia CIRP, vol. 55, pp. 290295, // 2016.

[4] L. Atzori, A. Iera, and G. Morabito, "The internet of things: A survey," Computer networks, vol. 54, pp. 2787-2805, 2010.

[5] T. Stock and G. Seliger, "Opportunities of Sustainable Manufacturing in Industry 4.0," Procedia CIRP, vol. 40, pp. 536-541, 2016/01/01 2016.

[6] A. Dietmair and A. Verl, "A generic energy consumption model for decision making and energy efficiency optimisation in manufacturing," International Journal of Sustainable Engineering, vol. 2, pp. 123-133, 2009.

[7] C. o. t. E. Communities, An Energy Policy for Europe vol. COM 1, 2007.

[8] A. Dietmair and A. Verl, "Energy consumption forecasting and optimisation for tool machines," Energy, vol. 62, p. 63, 2009.

[9] C. Herrmann and S. Thiede, "Process chain simulation to foster energy efficiency in manufacturing," CIRP Journal of Manufacturing Science and Technology, vol. 1, pp. 221-229, // 2009.
[10] D. J. Leeds, "The smart grid in 2010: market segments, applications and industry players," Gtm Research, pp. 1-145, 2009.

[11] C.-W. Park, K.-S. Kwon, W.-B. Kim, B.-K. Min, S.-J. Park, I.-H. Sung, et al., "Energy consumption reduction technology in manufacturingA selective review of policies, standards, and research," International Journal of Precision Engineering and Manufacturing, vol. 10, pp. 151173, 2009.

[12] J. Qin, Y. Liu, and R. Grosvenor, "A Categorical Framework of Manufacturing for Industry 4.0 and Beyond," Procedia CIRP, vol. 52, pp. 173-178, 2016.

[13] H. Kagermann, J. Helbig, A. Hellinger, and W. Wahlster, Recommendations for Implementing the Strategic Initiative INDUSTRIE 4.0: Securing the Future of German Manufacturing Industry; Final Report of the Industrie 4.0 Working Group: Forschungsunion, 2013.

[14] D. L. Bourell, M. C. Leu, and D. W. Rosen, "Roadmap for additive manufacturing: identifying the future of freeform processing," The University of Texas at Austin, Austin, TX, 2009.

[15] D. D. Gajski, F. Vahid, S. Narayan, and J. Gong, Specification and design of embedded systems: Prentice Hall Englewood Cliffs, 1994.

[16] S. Madakam, R. Ramaswamy, and S. Tripathi, "Internet of Things (IoT): A literature review," Journal of Computer and Communications, vol. 3, p. 164, 2015.

[17] A. M. Ortiz, D. Hussein, P. Soochang, S. N. Han, and N. Crespi, "The Cluster Between Internet of Things and Social Networks: Review and Research Challenges," Internet of Things Journal, IEEE, vol. 1, pp. 206215, 2014.

[18] M. Chen, S. Mao, and Y. Liu, "Big data: a survey," Mobile Networks and Applications, vol. 19, pp. 171-209, 2014.

[19] M. Minelli, M. Chambers, and A. Dhiraj, "Big data technology," Big Data, Big Analytics: Emerging Business Intelligence and Analytic Trends for Today's Businesses, pp. 61-88, 2013.

[20] R. Paul and S. Anand, "Process energy analysis and optimization in selective laser sintering," Journal of Manufacturing Systems, vol. 31, pp. 429-437, 2012.

[21] Q. Han, R. Setchi, and S. L. Evans, "Synthesis and characterisation of advanced ball-milled Al-Al 2 O 3 nanocomposites for selective laser melting," Powder Technology, vol. 297, pp. 183-192, 2016.

[22] M. Baumers, C. Tuck, R. Wildman, I. Ashcroft, and R. Hague, "Energy inputs to additive manufacturing: does capacity utilization matter?," EOS, vol. 1000, pp. 30-40.

[23] K. Kellens, E. Yasa, W. Dewulf, and J. Duflou, "Environmental assessment of selective laser melting and selective laser sintering," Going Green - Care Innovation: From Legal Compliance to Energyefficient Products and Services, Paper, p. 5, 2010.

[24] R. Sreenivasan and D. Bourell, "Sustainability Study in Selective Laser Sintering- An Energy Perspective," ed: Minerals, Metals and Materials Society/AIME, 420 Commonwealth Dr., P. O. Box 430 Warrendale PA 15086 USA, 2010.

[25] J. Watson and K. Taminger, "A decision-support model for selecting additive manufacturing versus subtractive manufacturing based on energy consumption," Journal of Cleaner Production, 2015.

[26] C. Telenko and C. C. Seepersad, "Assessing energy requirements and material flows of selective laser sintering of Nylon parts," in Proceedings of the Solid Freeform Fabrication Symposium 2010, 2010, pp. 8-10.08.

[27] K. Kellens, E. Yasa, R. Renaldi, W. Dewulf, J.-P. Kruth, and J. Duflou, "Energy and Resource Efficiency of SLS/SLM Processes (Keynote Paper)," in SFF Symposium 2011, 2011, pp. 1-16.

[28] X. Xu, S. Meteyer, N. Perry, and Y. F. Zhao, "Energy consumption model of Binder-jetting additive manufacturing processes," International Journal of Production Research, vol. 53, pp. 7005-7015, 2015.

[29] M. Baumers, C. Tuck, D. Bourell, R. Sreenivasan, and R. Hague, "Sustainability of additive manufacturing: measuring the energy consumption of the laser sintering process," Proceedings of the Institution of Mechanical Engineers, Part B: Journal of Engineering Manufacture, vol. 225, pp. 2228-2239, 2011.

[30] EOS, "EOSINT P700 Operation User Manual," 2004.

[31] J. Han, M. Kamber, and J. Pei, Data mining: concepts and techniques: Elsevier, 2011. 